\title{
Mycosis fungoides as casus pro diagnosi
}

\section{Katarzyna Borowska', Tomasz Wasyłyszyn²}

${ }^{1}$ Department of Histology and Embryology with Experimental Cytology Unit, Medical University of Lublin, Lublin, Poland, ${ }^{2}$ Department of Dermatology, Military Institute of Medicine in Warsaw, Poland

Corresponding author: Prof. Katarzyna Borowska, E-mail: k_borowska@wp.pl

Sir,

Cutaneous T cell lymphoma (CTCL) is a rare group of lymphoproliferative disorders characterized by localization of $\mathrm{T}$ lymphocytes to the skin. The most common subtype of CTCL is mycosis fungoides (MF) [1].

An 29-year-old polish women visited our outpatient clinic in 2011. The clinical picture at that time was very much similar to atopic dermatitis. Predominant symptoms were mild to moderate lichenisatio, most evident on extremities near the joints and in the neck. Itching was not present. Further examination revealed enlarged lymph nodes in all accessible locations. Therefore, the patient was administered with a HIV examination and topical treatment with $1 \%$ hydrocortisone ointment on the eucerine base. She was told to come back after a few weeks with the results. However, due to the fact that the patient worked in another country, she was not able to continue the treatment. She appeared for a second visit in June 2016. The result of HIV test turned out to be negative. She experienced subjectively the feeling of discomfort and weakness which she described as "permanent flu condition" and severe itching. The clinical picture was very different than that on the first visit. The lymph nodes became even more palpable or even visible without palpation (Fig. 1). According to the patient, lesions started to develop rapidly few months before the second visit. Clinically, there was exfoliative dermatitis (Figs. 2 and 3) involving about $50 \%$ of the skin surface with skin locally thickened and swollen (on arms) and hyperpignemted. She was referred to a dermatological clinic with an initial diagnosis of MF as casus pro diagnosi.

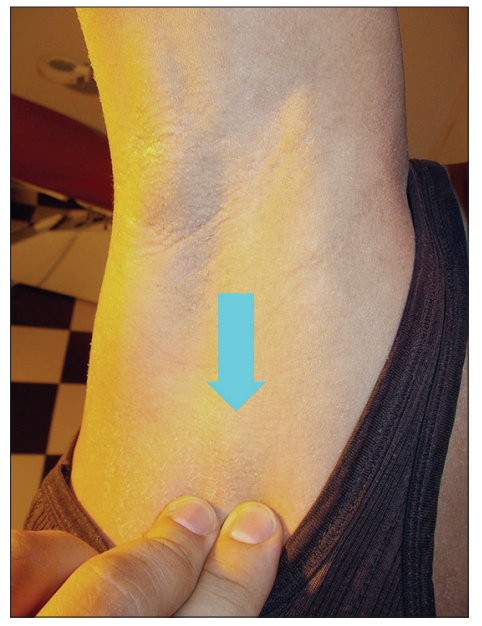

Figure 1: Axillary area with palpable lymph node (arrow).

Mycosis fungoides (MF) is the most common subtype of primary cutaneous T-cell lymphomas (CTCL), defined by skin-only involvement without extracutaneous spread at the time of presentation with an overall incidence of 10.2 cases per million person-years [1]. The peak age at presentation is in excess of 55 to 60 years $[2,3]$. There is a male predominance in almost all studies on CTCLs and MF, with a male:female ratio of 1.3:1 to 2:1 [4,5]. Mycosis fungoides is a disease mainly seen in older patients. We describe an 29-year-old woman with initial diagnosis of $\mathrm{MF}$ as casus pro diagnosi.

MF typically presents as skin patches and/or plaques, which can progress to skin tumours, with subsequent involvement of lymphnodes, peripheral blood, and visceral organs [6]. Less than one-third of patients develop advanced disease involving lymph nodes, blood, and visceral organs. Currently, many clinicopathologic variants of mycosis fungoides have been described [6]. Folliculotropic MF is important to recognize because 


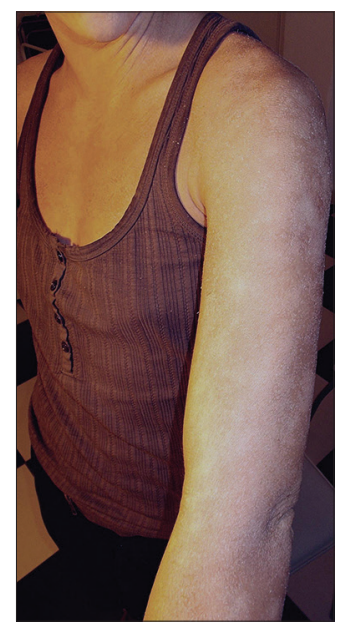

Figure 2: Exfoliative dermatitis of upper extremities with notable hyperpigmentation.

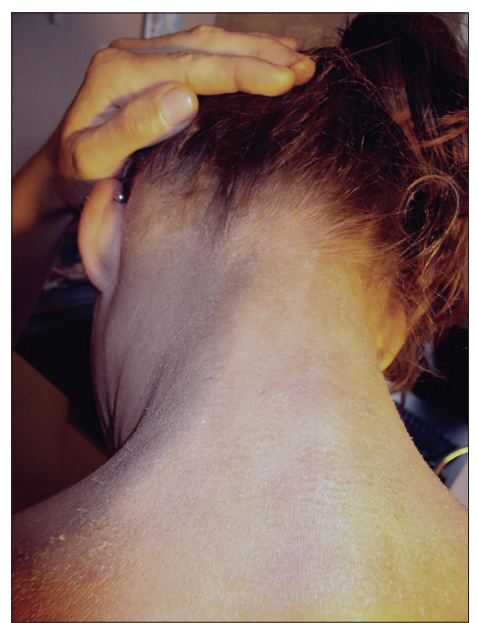

Figure 3: Neck area with swollen lymph nodes and exfoliative dermatitis.

it may imply a worse prognosis, with 5-year survival rates of approximately $60 \%$ to $70 \%$, and may require more intensive treatment [3]. Demographic features including African-American race, male gender, and age have been found to be risk factors for cutaneous $\mathrm{T}$ cell lymphoma (CTCL), while the extent of skin involvement, overall disease stage, and age are prognostic indicators [7]. The above mentioned case should be differentiated with Sezary syndrome, other T-cell lymphoma with large skin involvement (usually erythroderma). The latter one however often includes eye anomalies, palmoplantar keratosis and nail atrophy neither of which was present in this patient. MF is characterized by a long-term disease course, slow progression and favourable prognosis, in which it resembles indolent nodal non-Hodgkin's lymphomas. Clinically, in the early stages, MF manifests with itchy patches and plaques that strongly assimilate benign dermatoses, i.e., eczema, psoriasis vulgaris or lichen planus, and therefore represents a diagnostic challenge for dermatologists and pathologists.

\section{REFERENCES}

1. Korgavkar K, Xiong M, Weinstock M. Changing incidence trends of cutaneous T-cell lymphoma. JAMA Dermatol. 2013;149:1295-9.

2. Criscione VD, Weinstock MA. Incidence of cutaneous T-cell lymphoma in the United States, 1973-2002. Arch Dermatol. 2007;143:854-9.

3. Agar NS, Wedgeworth E, Crichton S, Mitchell TJ, Cox M, Ferreira S, et al., Survival outcomes and prognostic factors in mycosis fungoides/Sézary syndrome: validation of the revised International Society for Cutaneous Lymphomas/European Organisation for Research and Treatment of Cancer staging proposal. J Clin Oncol. 2010;28:4730-9.

4. Wilcox RA. Cutaneous T-cell lymphoma: 2014 update on diagnosis, risk-stratification, and management. Am J Hematol. 2014;89:837-51.

5. Tahmasebi B, Mahmoudi M, Yahyapour Y, Jamshidi M, Halakoie Naini K. Determination and comparison of incidence rate and trend of morbidity of leukemia and lymphoma in Mazandaran province (1376-1382). J Mazandaran Univ Med Sci. 2006;54:87-9.

6. Willemze R, Jaffe ES, Burg G, Cerroni L, Berti E, Swerdlow SH, et al. WHO-EORTC classification for cutaneous lymphomas. Blood. 2005;105:3768-85.

7. Imam MH, Shenoy PJ, Flowers CR, Phillips A, Lechowicz MJ. Incidence and survival patterns of cutaneous T-cell lymphomas in the United States. Leuk Lymphoma. 2013;54:752-9.

Copyright by Katarzyna Borowska, et al. This is an open-access article distributed under the terms of the Creative Commons Attribution License, which permits unrestricted use, distribution, and reproduction in any medium, provided the original author and source are credited.

Source of Support: Nil, Conflict of Interest: None declared. 